\title{
EFEITOS DA REGULAÇÃO DA AGÊNCIA NACIONAL DE SAÚDE SUPLEMENTAR (ANS) SOBRE A DISTRIBUIÇÃO DE RESULTADOS EM OPERADORAS DE PLANOS DE SAÚDE ${ }^{1}$
}

\section{EFFECTS OF SUPPLEMENTARY HEALTH AGENCY (ANS) REGULATION ON THE PAYOUT RATIO IN HEALTHCARE PROVIDERS}

\author{
Ewerton Alex Avelar \\ Doutor em Administração (UFMG) \\ Universidade Federal de Minas Gerais \\ ewertonalexavelar@gmail.com \\ Adriana Saraiva Souza \\ Graduada em Ciências Contábeis (UFMG) \\ adriana.saraivasouza@gmail.com \\ Caroline Garonce Ferreira \\ Graduanda em Administração (UFMG) \\ carolgaronce@gmail.com \\ Sabrina Amélia de Lima e Silva \\ Doutora em Administração (UFMG) \\ silva.saamelia@gmail.com \\ Antônio Artur de Souza \\ Ph.D. em Management Science (Lancaster University) \\ Universidade Federal de Minas Gerais (UFMG) \\ antonioarturdesouza@gmail.com
}

\section{RESUMO}

Objetivo: Este artigo apresenta os resultados de uma pesquisa que visou analisar os efeitos da regulação da Agência Nacional de Saúde Suplementar (ANS) sobre a distribuição de resultados em operadoras de planos de saúde (OPS) das modalidades de cooperativa médica (COM) e medicina de grupo (MDG).

Fundamento: A distribuição de resultados é uma das principais decisões em finanças corporativas. Diversos estudos têm analisado variáveis que influenciam tal decisão, porém, estes usualmente se referem a empresas de capital aberto e não abordam o papel da regulação.

\footnotetext{
${ }^{1}$ Artigo recebido em: 22/09/2019. Revisado por pares em: 05/05/2020. Reformulado em: 30/05/2020. Recomendado para publicação: 06/08/2020 por Vagner Antônio Marques (Editor Adjunto). Publicado em: 07/09/2020. Organização responsável pelo periódico: UFPB
} 
Método: A pesquisa pode ser classificada como descritiva, quantitativa e causal. Foram empregados dados secundários coletados junto à ANS entre 2010 e 2016. Empregaram-se as seguintes técnicas para análise de dados: estatística descritiva e análise de regressão com dados em painel.

Resultados: Constatou-se que as MDG distribuíram maior porção média de seus resultados em relação às COM. Ambos os modelos estimados apresentaram alto poder explicativo, indicando uma adequabilidade das variáveis tradicionais para a explicação do fenômeno. Em relação às variáveis de regulação, observou-se que a região de atuação das OPS foi a principal variável determinante na distribuição de resultados.

Contribuições: A pesquisa: (a) auxiliou a suprir uma lacuna teórica na literatura brasileira sobre a distribuição de resultados em organizações com capital fechado; (b) evidenciou o papel da regulação de um setor como variável determinante desse fenômeno; (c) demonstrou a validade de variáveis tradicionais para explicar a distribuição de resultados em OPS; e (d) propôs variáveis regulatórias para auxiliar no estudo desse fenômeno na saúde suplementar.

Palavras-chave: Regulação. Distribuição de resultados. Agência Nacional de Saúde Suplementar (ANS). Operadoras de Planos de Saúde (OPS).

\section{ABSTRACT}

Objective: This paper presents the results of a study that aimed at analyzing the determinants of payout ratio of Brazilian healthcare providers (OPS) under the Supplementary Health Agency (ANS) regulation. It focuses on OPS classified as medical cooperative (COM) and group medicine (MDG).

Foundation: The dividend policy is one of the most important decisions in corporative finance. Several studies have analyzed the variables that explained this decision. However, these studies usually focus on public companies and they do not address the regulation role.

Methodology: The developed research can be classified as a quantitative, descriptive and explanatory one. The employed sample consisted of healthcare OPS whose 2010-2016 data are publicly available on the ANS website. Data analysis followed these techniques: descriptive statistics, and data panel regression.

Results: We verified that the MDG distribute higher portion of their results compared to COM. The estimated models fit the data very well, what indicates the adequacy of traditional variables for explaining the phenomenon. In relation to regulation variables, we observed that the region of location of OPS was the major determinant variable for explaining payout ratios.

Contributions: The developed research offers a range of contributions, such as: (a) it addressed the gap in literature about payout in private companies; (b) enhanced the relevance of regulation in explaining payout ratios; (c) it also indicated the validity of traditional variables in models, as a way of explaining OPS payout; and (d) it proposed regulatory variables to help explain this phenomenon on these organizations.

Keywords: Regulation. Payout. Supplementary Health Agency (ANS). Healthcare providers (OPS).

\section{INTRODUÇÃO}

Normalmente, a decisão de distribuição de resultados em uma organização é denominada como "decisão de dividendos" em finanças corporativas (Damodaran, 2004). Segundo Holanda e Coelho (2012), os dividendos podem ser definidos como a parcela realizada da remuneração do capital que está investido na empresa sob a perspectiva do investidor. Pode-se dizer que o valor de uma organização, para o investidor, tem influência na política de dividendos por ela adotada, de 
forma que enxergam nos resultados distribuídos o potencial lucrativo da organização (Leite, Bambino, \& Hein, 2017). Uma política de dividendos consiste na implementação de uma deliberação da administração da entidade com relação à parcela do lucro a ser retido e, consequentemente, com relação à parcela que será distribuída aos proprietários (Fonteles, Peixoto, Vasconcelos, \& De Luca, 2012).

Diversos estudos recentes no Brasil abordaram especificamente as variáveis que influenciam a política de distribuição de resultados em empresas nacionais, tais como: Ferreira, Nakamura, Martin e Bastos (2010), Fonteles et al. (2012), Holanda e Coelho (2012), Chiarello, Silva e Nakamura (2014), Forti, Peixoto, Lima e Alves (2015), Januzzi, Avelar e Amaral (2015) e Vancin e Procianoy (2016). Tais estudos destacaram diversos aspectos específicos das empresas e de seu ambiente que poderiam influenciar a política de distribuição de resultados. Contudo, todos esses trabalhos estudaram apenas empresas de capital aberto. Além disso, os referidos trabalhos não enfocaram o aspecto da regulação como um possível determinante em alguns setores, tal como ressaltam estudos internacionais como Ang, Fatemi e Tourani-Rad (1997), Fama e French (2002) e Cornett, Fayman, Marcus e Tehranian (2011).

Nesse sentido, é importante salientar que, no Brasil, um importante setor, formado essencialmente por organizações de capital fechado e que sofre com intensa regulação, é o setor das operadoras de planos de saúde (OPS). Pinheiro, Peleias, Silva e Martins (2015) e Silva e Lobel (2016) ressaltam que essas organizações são estreitamente reguladas pela Agência Nacional de Saúde Suplementar (ANS), que influencia significativamente nas decisões financeiras tomadas pelos seus administradores. Ressalta-se que a Resolução de Diretoria Colegiada (RDC) n .39 (2000) da referida agência classifica as OPS em diferentes modalidades. Dentre essas, duas se destacam por serem as mais comuns no país e apresentarem o maior número de beneficiários: cooperativas médicas (COM) e medicina de grupo (MDG).

Diante do exposto, este artigo apresenta os resultados de uma pesquisa que visou analisar os efeitos da regulação da ANS sobre a distribuição de resultados em OPS das modalidades COM e MDG, entre os anos de 2010 e 2016. Nesse sentido, foram propostos os seguintes objetivos específicos: (a) identificar variáveis regulatórias da ANS que têm potencial de influenciar as decisões de distribuição de resultados nas OPS estudadas; (b) estimar modelos que evidenciem a relação entre a distribuição de resultados e as variáveis selecionadas; e (c) discutir as implicações para as operadoras estudadas (COM e MDG).

A pesquisa apresentada neste artigo se justifica sob diversos aspectos. Primeiramente, temse a escassez na literatura nacional sobre a distribuição de resultados em organizações que não sejam empresas de capital aberto, tal como evidenciado nos estudos supracitados. Ademais, destaca-se a falta de pesquisas que enfoquem os efeitos da regulação de um dado setor sobre essa política nas organizações. Dessa forma, a pesquisa ora apresentada contribui para cobrir esta lacuna teórica.

Além disso, salienta-se a importância das OPS para o sistema de saúde do país: dados da ANS indicam que existem 262 ativas classificadas como MDG, que são responsáveis pelo atendimento a mais de 18,3 milhões de beneficiários em planos médico-hospitalares (maior abrangência do país); enquanto as OPS classificadas como COM são as mais comuns (292 ativas) e que atendem a mais de 17,4 milhões de beneficiários (ANS, 2019). Xavier (2017) também ressalta desafios gerenciais nas OPS, que se encontram em um ambiente com escassez de recursos, alto custo de procedimentos e alta complexidade da gestão. Nesse sentido, segundo a Associação Brasileira de Planos de Saúde (ABRAMGE), muitas OPS médico-hospitalares estão em fase final de liquidação devido à problemas de gestão (ABRAMGE, 2015). 


\section{REVISÃO DA LITERATURA}

\subsection{Distribuição de Resultados}

Vancin e Procianoy (2016, p. 90) definem dividendo como "uma parcela do lucro líquido das empresas que é distribuída aos investidores, como uma forma de remuneração do capital investido". Viana e Ponte (2016) salientam que cabe à organização decidir o que fará com o resultado da mesma: se irá distribuí-lo ou preferirá retê-lo para aplicações e investimentos. Conforme esses autores, caso a organização opte por reter parte do resultado, deverá, também, dizer à proporção que será feito.

Nesse contexto, Silva e Machado (2015, p. 9) descrevem a política de dividendos como "decisões relacionadas ao que fazer com o lucro líquido da empresa, ou seja, distribuí-los aos acionistas, na forma de dividendos, ou reinvesti-los, como fonte de financiamentos de projetos geradores de valor". De acordo com Damodaran (2004), a decisão de reter lucros pressupõe que o retorno gerado pela empresa supera o ganho que o acionista poderia obter na hipótese de dispor desses valores.

De maneira geral, as políticas de distribuição de resultados adotadas pelas organizações tendem a acompanhar seu ciclo de vida. As mais jovens normalmente não possuem políticas específicas nesse sentido, ou escolhem reter resultados para investir ou precaver-se quanto ao cenário incerto dos anos posteriores, enquanto as organizações mais maduras prezam pela política por enxergarem que os fornecedores de capital terão maior confiança de anos prósperos (Damodaran, 2004). Nesse sentido, a distribuição de resultados estaria diretamente relacionada com a estabilidade da organização frente às incertezas do mercado.

O cenário brasileiro, quanto à distribuição do lucro líquido, possui dois componentes: os dividendos e os juros sobre capital próprio. Segundo Silva e Machado (2015, p. 10), a legislação societária brasileira estabelece que o "estatuto da própria sociedade por ações é quem determina qual a parcela do lucro a ser distribuída como dividendo obrigatório, não sendo permitido ser inferior a 25\% do lucro líquido ajustado". Desde o início de 1996 não existe tributação incidindo nos lucros distribuídos, de forma que os investidores os recebem integralmente (Viana \& Ponte, 2016).

Já acerca dos Juros Sobre o Capital Próprio, Silva e Machado (2015) destacam a Lei n. 9.249 (1995), em substituição à correção monetária dos balanços no Brasil. Tais autores defendem que a vantagem da utilização desse método para a remuneração dos acionistas está relacionada ao Imposto de Renda, que traria economia para as empresas. Em contrapartida, as empresas cujos juros sobre capital próprio é excessivo, e não são utilizados no que tange à política de dividendos têm, frente aos acionistas, sua visão de valor da empresa fragilizada (Silva \& Machado, 2015).

Nesse sentido, Gelbcke, Santos, Iudícibus e Martins (2018) acrescentam que a Lei n. 9.249 (1995) visa evitar um possível aumento da carga tributária incidente sobre as empresas após a extinção da correção monetária sistemática das demonstrações financeiras, uma vez que tais juros são dedutíveis para fins de cálculo dos principais tributos sobre o lucro. E afirmam, ainda, que os juros sobre capital próprio são calculados com base na aplicação da taxa de juros de longo prazo (TJLP) sobre o patrimônio líquido total da empresa (exceto reserva de reavaliação), sendo que o seu valor é limitado a: (a) 50\% do lucro líquido do exercício antes da dedução desses juros; ou (b) $50 \%$ do somatório dos lucros acumulados e reservas de lucros (Gelbcke et al., 2018).

Já no caso das cooperativas, a distribuição de seus resultados é realizada proporcionalmente à contribuição individual de cada cooperado. Segundo a Lei n. 5.764 (1971), a Assembleia Geral Ordinária da cooperativa é responsável por deliberar sobre a distribuição de resultados auferidos, sejam eles "sobras" ou não (Lei n. 5764, 1971). Ainda, segundo a referida lei, devem-se formar fundos antes dessa distribuição, quais sejam: (i) Fundo de Reserva destinado a reparar perdas e atender ao desenvolvimento de suas atividades, constituído com $10 \%$ (dez por cento), pelo menos, das sobras líquidas do exercício; (ii) Fundo de Assistência Técnica, Educacional e Social, destinado à 
prestação de assistência aos associados, seus familiares e, quando previsto nos estatutos, aos empregados da cooperativa, constituído de 5\% (cinco por cento), pelo menos, das sobras líquidas apuradas no exercício; e (iii) outros fundos criados pela assembleia geral (Lei n. 5764, 1971). Nesse sentido, Barroso e Bialoskorski (2010) ressaltam que os resultados obtidos pela cooperativa são distribuídos aos seus associados independente do valor, ou seja, da mesma forma que os ganhos são repartidos entre os cooperados, os prejuízos também são divididos.

\subsection{Variáveis que Influenciam a Distribuição de Resultados}

Conforme Forti et al. (2015), entender quais variáveis influenciam as organizações em suas decisões de distribuição e retenção de caixa é importante para gestores financeiros, investidores e para os órgãos reguladores de mercado. Isso porque as organizações, como apresentam Ross, Westerfield, Jaffe e Lamb (2015), encaram a decisão de distribuição de resultados como de grande importância, uma vez que é por meio dela que se determinam os volumes de recursos distribuídos e os retidos para reinvestimento. As variáveis que influenciam o pagamento, também chamadas variáveis determinantes de política de dividendos, podem ser indicadores que caracterizam a política de distribuição de resultados (Santos \& Galvão, 2015).

Para Fama e French (2001), existem três principais características que afetam a decisão de distribuição de resultados: lucratividade, oportunidades de investimento e tamanho; assim sendo, empresas maiores e mais rentáveis são mais propensas a distribuir resultados. Santos e Galvão (2015) acreditam que essas variáveis se referem à rentabilidade, endividamento, liquidez, controle de propriedade, tamanho, risco, ciclo de vida, setor econômico, governança corporativa, oportunidade de crescimento/investimento, aspectos de mercado, disponibilidade de caixa, efeito clientela, variação dos lucros e tributação.

Em consonância com essa ideia, Forti et al. (2015) destacam relações da distribuição de resultados pelas organizações brasileiras, por eles analisadas, afirmando serem baseadas nas teorias clássicas de finanças. Além disso, esses autores identificaram relações positivas entre a distribuição de resultados e o tamanho da firma, retorno, market to book, liquidez, controle e crescimento dos lucros, enquanto com alavancagem, governança corporativa, risco e assimetria informacional obtiveram relações negativas.

Salienta-se que estudos empíricos nacionais e internacionais têm apresentado variáveis que influenciam a política de distribuição de resultados das organizações. Algumas dessas variáveis são apresentadas no Quadro 1. Destaca-se que as variáveis supracitadas foram empregadas em diferentes contextos e apresentaram, algumas vezes, resultados divergentes do esperado pela literatura. Todavia, elas apresentam consistência teórica no que tange à política de distribuição de resultados das organizações. 


\begin{tabular}{|l|l|l|l|}
\hline Variável & Sigla & Fórmula & Fonte \\
\hline Custo Financiamento & CFIN & $\begin{array}{l}\text { Despesa Financeira } \div \text { Financi- } \\
\text { amentos (curto e longo prazos) }\end{array}$ & $\begin{array}{l}\text { Vancin e Procianoy (2016) e } \\
\text { Fiorati, Garcia e Tambosi } \\
(2007)\end{array}$ \\
\hline $\begin{array}{l}\text { Investimento no ativo não cir- } \\
\text { culante }\end{array}$ & INVPERM & $\begin{array}{l}\text { (Ativo não circulante - Ativo } \\
\text { Realizável a Longo prazo) } \div \\
\text { Ativo Total }\end{array}$ & $\begin{array}{l}\text { Januzzi et al. (2015) e Wool- } \\
\text { ridge e Gosh (1985) }\end{array}$ \\
\hline $\begin{array}{l}\text { Multiplicador de Alavancagem } \\
\text { Financeira }\end{array}$ & MAF & $\begin{array}{l}\text { (Passivo Circulante + Passivo } \\
\text { não circulante) } \div \text { Patrimônio } \\
\text { Líquido }\end{array}$ & Ferreira et al. (2010) \\
\hline Necessidade de Capital de Giro & NCG & $\begin{array}{l}\text { (Ativo operacional - Passivo } \\
\text { operacional) } \div \text { Ativo Total }\end{array}$ & Januzzi et al. (2015) \\
\hline Retorno sobre o Ativo (ROA) & ROA & Lucro Líquido $\div$ Ativo Total & $\begin{array}{l}\text { Vancin e Procianoy (2016) e } \\
\text { Forti et al. } \text { (2015) }\end{array}$ \\
\hline Tamanho & TAM & Ln (Ativo Total) & $\begin{array}{l}\text { Vancin e Procianoy (2016) e } \\
\text { Forti et al. (2015) }\end{array}$ \\
\hline
\end{tabular}

Quadro 1: Variáveis que influenciam a política de dividendos nas organizações.

Fonte: elaborado pelos autores.

O Custo de Financiamento (CFIN) é a forma que a organização opta pra investir em seu crescimento, podendo ser interno (utilizando capital próprio) ou externo (buscando financiamento com capital de terceiros). Ambas as opções acarretam numa retenção de lucro e, consequentemente, afetam a política de distribuição de resultados adotada. É comum, no contexto brasileiro, que as organizações optem por não distribuí-los, a fim de reter os resultados obtidos e conseguir autofinanciamento (Vancin \& Procianoy, 2016; Fiorati et al., 2007).

Já o Investimento no Ativo Não-Circulante (INVPERM) trata de uma alocação do capital disponível da organização que pode ser aproveitado para investir em ativos de longo prazo, dessa forma, contribuindo para ganho monetário de ativos para a organização. Assim, a organização teria uma valorização de seu valor de mercado. No entanto, salienta-se que, de modo geral, o mercado reage de forma negativa a uma regressão na política de distribuição de resultados, ainda que o investimento seja rentável (Vancin \& Procianoy, 2016).

A variável Multiplicador de Alavancagem Financeira (MAF) é associado à capacidade de endividamento para aumentar a rentabilidade. Essa variável influencia organizações, principalmente as de menor porte, em relação à distribuição de resultados. Apesar de uma alta alavancagem significar um fluxo de caixa elevado para o futuro, é esperado que as organizações optem por distribuir seus resultados (Ferreira et al., 2010).

A variável Necessidade de Capital de Giro (NCG), utilizada para análise financeira da organização, é obtida a partir do resultado entre o Ativo Operacional (AO) e o Passivo Operacional (PO), podendo sofrer variações positivas e negativas em decorrência do ciclo operacional da organização (Monteiro, 2003). O preço do estoque, variações dos níveis de atividade econômica, bem como aumentos e reduções dos prazos de pagamentos dos fornecedores e recebimentos dos clientes são algumas das causas que influenciam a NCG (Seidel \& Kume, 2003). Assim, espera-se que uma maior NCG implique em um menor volume de distribuição de resultados (Januzzi et al., 2015).

Acredita-se que as organizações tendem a distribuir resultados quando há uma maior rentabilidade (Vancin \& Procianoy, 2016). Do ponto de vista da organização, quando há um maior Retorno sobre o Ativo (ROA), que demonstra ter havido maior rentabilidade, consequentemente as organizações sentem-se mais seguras a distribuir mais resultados, visto que, para manter uma crescente política de pagamento de distribuição de resultados, é preciso também um proporcional crescimento rentável (Forti et al., 2015). 
Por fim, a variável Tamanho (TAM) possui proporcionalidade em relação à distribuição de resultados, isto é, organizações maiores têm maior propensão a distribuir maior volume de resultados (Vancin \& Procianoy, 2016). No caso das OPS, essa relação está ligada também ao número de beneficiários, uma vez que, quanto maior o número de beneficiários, maior tende a ser a organização e, consequentemente, maior a distribuição de resultados. No estudo ora apresentado, empregou-se como proxy o tamanho do ativo, pois há uma correlação positiva e significante entre esta variável contábil e o número beneficiários (coeficiente de 0,54 e significante a menos de 1,0\%). Segundo Fama e French (2001), organizações de grande porte possuem maior facilidade de obter financiamento, podendo assim distribuir mais resultados.

Diversos estudos foram realizados no Brasil, ao longo da última década, sobre a influência de variáveis sobre a política de distribuição de resultados por parte de empresas nacionais. Dentre esses estudos, podem ser citados: Ferreira et al. (2010), Fonteles et al. (2012), Holanda e Coelho (2012), Chiarello et al. (2014), Forti et al. (2015), Januzzi et al. (2015), Silva e Machado (2015) e Vancin e Procianoy (2016).

Apesar de ser um tema recorrente na literatura nacional, observa-se que os estudos supracitados enfocam exclusivamente empresas de capital aberto, ou seja, não são encontrados estudos sobre esse fenômeno em organizações de capital fechado. Ademais, nenhum dos estudos citados empregou variáveis relacionadas à regulação do setor de atuação (normalmente são usadas variáveis como as relacionadas ao Quadro 1). Porém, a regulação é citada como uma variável que pode ser significante em determinados setores, no que tange à distribuição de resultados, segundo alguns estudos internacionais, tais como Ang et al. (1997), Fama e French (2002) e Cornett et al. (2011).

\subsection{Regulação e Distribuição de Resultados em Operadoras de Planos de Saúde (OPS)}

Apesar de a operação de planos de saúde acontecer há mais de 40 anos no país, ela só passou a ser regulada em 1998, por meio da Lei no 9.656 (1998), que disciplinou o funcionamento desses planos e a atuação das organizações que poderiam ser definidas como OPS (Ugá, Lima, Portela, \& Barbosa, 2008). Veloso e Malik (2010) ressaltam que a regulação da ANS levou a limitações no aumento dos prêmios, à padronização de coberturas de atendimento e a uma menor diferenciação entre as OPS, ao mesmo tempo em que houve uma grande ampliação nos direitos dos usuários.

Uma OPS pode ser definida como uma pessoa jurídica constituída sob a modalidade de sociedade civil ou comercial, cooperativa, ou entidade de autogestão, que opere produto, serviço ou contrato de Plano Privado de Assistência à Saúde (Lei no . 9656, 1998). O Plano Privado de Assistência à Saúde é considerado uma prestação continuada de serviços ou cobertura de custos assistenciais a um preço pré ou pós-estabelecido, por prazo indeterminado, no intuito de garantir, sem limite financeiro, a assistência à saúde, pela faculdade de acesso e atendimento por profissionais ou serviços de saúde (Lei n⿳o.9 9656, 1998).

As OPS são classificadas de diferentes formas pela ANS. De acordo com a RDC nº. 39 (2000), essas OPS devem ser classificadas em uma das seguintes modalidades: administradora, cooperativa médica, cooperativa odontológica, autogestão, medicina de grupo, odontologia de grupo ou filantropia (RDC $\left.\mathrm{n}^{\circ} .39,2000\right)$. Na pesquisa apresentada neste trabalho, foram estudadas as OPS classificadas como MDG e COM. Segundo a ANS (2019), tais modalidades de operadoras são as que atendem ao maior número de beneficiários atualmente no Brasil e que possuem o maior número de organizações ativas.

Segundo a RDC nº 39 (2000) são classificadas como MDG as empresas ou entidades que operam planos privados de assistência à saúde, excluindo-se aquelas classificadas nas modalidades de administradora, cooperativa médica, autogestão e filantropia. Por sua vez, classificam-se como COM as sociedades de pessoas sem fins lucrativos, constituídas conforme a Lei n⿳o 5.764 
(1971) (Lei que institui o regime jurídico das sociedades cooperativas) e que operam Planos Privados de Assistência à Saúde. Conforme Machado (2009), as COM são cooperativas de trabalho cuja finalidade é proporcionar aos seus membros melhores condições para exercer sua profissão. Ainda conforme esse autor, essas cooperativas têm sido bem-sucedidas no campo da saúde suplementar no Brasil. Pode-se dizer que, ao comparar o desempenho das cooperativas com as outras modalidades de operadoras de saúde, observa-se que as mesmas são competitivas e eficientes (Machado, 2009).

Tais organizações (COM e MDG) atuam captando beneficiários em mercados muito semelhantes, ao contrário das de autogestão (que têm um mercado cativo) e das filantrópicas (que não têm fins lucrativos). Assim, com algumas restrições relacionadas aos ideais cooperativistas, todos os aspectos já expostos sobre distribuição de resultados aplicados às empresas podem ser aplicados no que tange a tais organizações. Contudo, as mesmas devem seguir a forte regulação da ANS, o que pode influenciar em sua política de distribuição de resultados. Com base nessa premissa, são tecidas, em sequência, algumas hipóteses sobre os efeitos da regulação da ANS sobre a distribuição de resultados nas OPS estudadas.

Ao se discutir a regulação de planos de saúde, é importante destacar que, com base na Ação de Inconstitucionalidade n⿳o. 1.931 de 2003, os planos de saúde contratados antes da regulação da ANS (conhecidos como "planos antigos") não se submetem às normas dessa agência, valendo o contrato entre as partes (OPS e beneficiários) (Supremo Tribunal Federal, 2003). Assim, como as OPS poderiam negociar de acordo com seus objetivos e situações de mercado, desenvolveu-se a Hipótese 1:

Hipótese 1 A proporção de contratos antigos em suas carteiras tem relação positiva e significante com a distribuição de resultados das OPS estudadas.

O reajuste de planos de saúde individuais é distinto dos coletivos (ligados a empresas e outras organizações). Segundo Varella e Ceschin (2014), enquanto os primeiros só podem ser reajustados com autorização da ANS, os planos coletivos, com algumas limitações, podem ser reajustados com base na negociação entre as partes. Assim, espera-se que as OPS tenham preferências pelos planos coletivos - tal como evidenciado por Leal (2014) - e, com base neles, consigam refletir variações em suas despesas e em seus preços, de acordo com seus interesses, mantendo uma política de distribuição de resultados favorável à organização. Com base nisso, desenvolveu-se a Hipótese 2:

A proporção de beneficiários de planos coletivos em suas carteiras tem relaHipótese 2 ção positiva e significante com a distribuição de resultados das OPS estudadas.

De acordo com a região de atuação da OPS, a ANS exige diferentes níveis de recursos próprios mínimos (Patrimônio Líquido Ajustado - PMA) e constituição de provisões técnicas, de acordo com a Resolução Normativa (RN) nº. 209 (2009). As seis regiões da ANS apresentadas na referida resolução são apresentadas no Quadro 2.

O PMA é o requisito mínimo de patrimônio que uma operadora deve possuir para operar em uma dada área, independentemente de seu porte, sendo uma espécie de "garantia" para a entrada no setor. Já as provisões técnicas representam o risco esperado, mensurado com base em critérios do negócio e exigem garantias reais (imóveis, títulos etc.) (Pinheiro et al., 2015). Uma vez que essas considerações têm relação direta com o patrimônio e o valor retido das OPS, desenvolveu-se a Hipótese 3:

Hipótese 3

A região de atuação da OPS tem relação significante com a distribuição de resultados das OPS estudadas. 


\begin{tabular}{|c|c|}
\hline Região & Descrição \\
\hline 1 & $\begin{array}{l}\text { OPS que atuam em todo o território nacional ou em grupos de, pelo menos, três estados dentre os } \\
\text { seguintes: São Paulo, Rio de Janeiro, Minas Gerais, Rio Grande do Sul, Paraná e Bahia. }\end{array}$ \\
\hline 2 & $\begin{array}{l}\text { OPS que atuam no Estado de São Paulo ou em mais de um estado, excetuando os grupos definidos } \\
\text { no critério da Região } 1 .\end{array}$ \\
\hline 3 & OPS que atuam em um único estado, qualquer que seja ele, excetuando-se o Estado de São Paulo. \\
\hline 4 & $\begin{array}{l}\text { OPS que atuam no Município de São Paulo, do Rio de Janeiro, de Belo Horizonte, de Porto } \\
\text { Alegre, de Curitiba ou de Brasília. }\end{array}$ \\
\hline 5 & OPS que atuam em grupo de municípios, excetuando os definidos na Região 4. \\
\hline 6 & OPS que atuam em um único município, excetuando os definidos na Região 4. \\
\hline
\end{tabular}

Quadro 2: Regiões de atuação das OPS.

Fonte: Elaborado com base na RN no. 209 (2009).

A ANS foi criada no ano 2000, pela Lei no․ 9.961 (2000). Compete a ela, segundo o Artigo 4으, inciso XXII, "autorizar o registro e o funcionamento das operadoras de planos privados de assistência à saúde, bem assim sua cisão, fusão, incorporação, alteração ou transferência do controle societário" (Lei n⿳. 9961, 2000). De acordo com a ANS (2018), para se obter o registro é necessário um processo composto por uma série de etapas. Conforme Veloso e Malik (2010) houve alterações na relação das OPS após essa criação. Contudo, anteriormente, não existiam limites específicos na atuação das operadoras mais antigas (Ugá et al., 2008). Assim, desenvolveu-se a Hipótese 4.

Hipótese 4

O fato de a OPS ter sido registrada após a criação da ANS tem relação negati-

va e significante com a distribuição de resultados das OPS estudadas.

A razão de dependência expressa "a relação percentual entre o número de menores de 15 anos, somados aos maiores de 60 anos sobre os beneficiários entre 15 e 59 anos" (ANS, 2016, p. 4). Nesse caso, uma vez que há, usualmente, uma busca maior por assistência médica entre crianças e idosos, espera-se que essa situação influencie a demanda interna de recursos das operadoras, de acordo com a proporção entre esses beneficiários e os beneficiários totais. Assim, desenvolveu-se a Hipótese 5. Para testar as hipóteses supracitadas em modelos econométricos, foi empregada uma série de variáveis (citadas no Quadro 3).

Hipótese 5 A razão de dependência das OPS tem relação negativa e significante com a distribuição de resultados das OPS estudadas.

\begin{tabular}{|c|l|l|l|l|}
\hline Hipótese & \multicolumn{1}{|c|}{ Variável } & Sigla & \multicolumn{1}{|c|}{ Cálculo } & Referências \\
\hline H1 & $\begin{array}{l}\text { Proporção de contra- } \\
\text { tos antigos }\end{array}$ & ANT & BPA $\div$ BTO & ANS (2018) \\
\hline H2 & $\begin{array}{l}\text { \% de beneficiários de } \\
\text { planos coletivos }\end{array}$ & COL & PCOL $\div$ (PCOL + PIND) & $\begin{array}{l}\text { Adaptado de ANS } \\
(2016)\end{array}$ \\
\hline H3 & $\begin{array}{l}\text { Região de atuação das } \\
\text { OPS }\end{array}$ & CDR & $\begin{array}{l}\text { Se a operadora atua em uma dada região (1 } \\
\text { a 5), 1; se não, 0. (Variável dummy) }\end{array}$ & RN n. 209 (2009) \\
\hline H4 & Registro ANS & RANS & $\begin{array}{l}\text { Se a operadora foi registrada antes da cria- } \\
\text { ção da ANS, 0; Se não, 1. (Variável dummy) }\end{array}$ & $\begin{array}{l}\text { Lei n. } \\
(2011)\end{array}$ \\
\hline H5 & Razão de dependência & DEP & M15M60 $\div$ OBE & ANS (2016) \\
\hline
\end{tabular}

Quadro 3: Operacionalização de variáveis relacionadas à regulação.

Fonte: Elaborado pelos autores.

Notas: BPA - Beneficiários de planos antigos; BTO - Total de beneficiários; M15M60 - Beneficiários menores de 15 anos e maiores de 60; OBE - Beneficiários maiores de 15 anos e menores de 60; PCOL - Beneficiários de coletivos; PIND - Beneficiários de planos individuais. 


\section{METODOLOGIA}

A pesquisa apresentada neste artigo pode ser classificada essencialmente como descritiva, quantitativa e causal. A pesquisa descritiva, segundo Malhotra e Birks (2007), é aquela cujo principal objetivo é a descrição de um dado fenômeno. Ainda conforme os mesmos autores, estudos de natureza causal têm como maior objetivo obter evidências de relações de causa e efeito. Já as pesquisas com enfoque quantitativo visam "testar hipóteses com base na medição numérica e na análise estatística para estabelecer padrões de comportamento" (Sampieri, Collado, \& Lucio, 2006, p. $5)$.

A Tabela 1 apresenta o número de OPS que compuseram a amostra. É importante destacar que foram coletados dados a partir de 2010, devido à significativa convergência das normas brasileiras de Contabilidade com as internacionais a partir do referido ano (Gelbcke et al., 2018). Já no caso do ano de 2016, este foi o ano mais recente que os pesquisadores tiveram acesso durante o período de desenvolvimento da pesquisa.

Tabela 1: Número de observações por ano e por modalidade.

\begin{tabular}{l|rrrrrrrr|r}
\hline Grupos de organizações & \multicolumn{1}{|l}{$\mathbf{2 0 1 0}$} & $\mathbf{2 0 1 1}$ & $\mathbf{2 0 1 2}$ & $\mathbf{2 0 1 3}$ & $\mathbf{2 0 1 4}$ & $\mathbf{2 0 1 5}$ & $\mathbf{2 0 1 6}$ & Total \\
\hline Cooperativa Médica & 304 & 241 & 290 & 287 & 289 & 287 & 283 & $\mathbf{1 . 9 8 1}$ \\
Medicina de Grupo & 242 & 235 & 199 & 194 & 185 & 191 & 188 & $\mathbf{1 . 4 3 4}$ \\
\hline
\end{tabular}

Fonte: Dados da pesquisa.

Para o desenvolvimento da pesquisa, foram empregados, essencialmente, dados secundários (financeiros e operacionais). Foram coletados, especialmente, dados financeiros provenientes das demonstrações financeiras publicadas pelas organizações que compuseram a amostra. É importante salientar que parte dos dados operacionais foi obtida a partir de solicitações diretas à ANS, fundamentadas na Lei no ${ }^{\circ} 12.527$ (2011), conhecida como Lei de Acesso à Informação (LAI).

Todos os dados das contas foram padronizados em um plano de contas padrão que atendesse aos objetivos dos pesquisadores. Posteriormente, os dados foram utilizados para calcular as variáveis demandadas para análise. É importante salientar que diversas revisões foram realizadas para garantir a integridade dos dados analisados.

Após a coleta e o tratamento dos dados, foram aplicadas as seguintes técnicas de análise sobre os mesmos: estatística descritiva e análise de regressão com dados em painel. A estatística descritiva consiste, conforme Mann (2006), em métodos para se organizar, exibir e descrever dados usando tabelas, gráficos e outras medidas resumidas. Na pesquisa ora apresentada, esta técnica foi empregada para se analisar medidas-resumo para a estimação de modelos econométricos.

No que se relaciona à análise de regressão com dados em painel, Fávero (2015) ressalta que ela possibilita que se compreenda o comportamento de fenômenos, características e outras unidades de observação ao longo de um período. Podem ser empregadas diferentes abordagens para a análise de dados em painel, sendo que a utilização de cada um dos modelos considera as características dos dados e as suas limitações inerentes (Fávero, 2015).

O modelo estimado é apresentado na Equação 1. Neste caso, a variável distribuição de resultados (DR) foi mensurada como o valor do resultado distribuído (em reais) no período, dividido pelo ativo total. Foram apresentadas como variáveis independentes (ligadas à regulação), aquelas listadas no Quadro 3 deste artigo.

Por sua vez, foram consideradas como variáveis de controle àquelas listadas no Quadro 1 (sendo que as mesmas foram divididas pelo ativo total, com exceção da variável "tamanho"). Ressalta-se que $\beta_{0}$ representa o intercepto; $\varepsilon$ representa o termo de erro e os subscritos $i$ e $t$ especificam, respectivamente, as observações quanto às organizações e aos anos abrangidos pelo estudo. 


$$
\begin{aligned}
D R_{i t}=\beta_{0}+\beta_{1} \times & C F I N_{i t}+\beta_{2} \times I N V P E R M_{i t}++\beta_{3} \times M A F_{i t}+\beta_{4} \times N C G_{i t}+\beta_{5} \times R O A_{i t}+\beta_{6} \\
& \times T A M_{i t}+\beta_{7} \times C O L_{i t}+\beta_{8} \times A N T_{i t}+\beta_{9} \times D E P_{i t}+\beta_{10} \times R A N S_{i t}+\beta_{11} \times C D R 1_{i t} \\
& +\beta_{12} \times C D R 2_{i t}+\beta_{13} \times C D R 3_{i t}+\beta_{14} \times C D R 4_{i t}+\beta_{15} \times C D R 5_{i t}+\varepsilon_{i t}
\end{aligned}
$$

Para avaliar a qualidade geral de ajustamento dos modelos estimados, empregaram-se o $\mathrm{R}^{2}$ ajustado e o Teste F, enquanto que, para análise dos resíduos, foram calculados os testes de Shapiro-Wilk, Breush-Pagan e Breusch-Godfrey/Wooldridge, para avaliar, respectivamente, possíveis problemas de normalidade, homoscedasticidade e autocorrelação, conforme recomendado por Gujarati e Porter (2011) e Fávero (2015). Ademais, para se testar o melhor modelo a ser estimado, empregou-se o teste de Hausman (Gujarati \& Porter, 2011). O Quadro 4 apresenta um resumo dos testes empregados na estimação dos modelos.

\begin{tabular}{|l|l|l|}
\hline \multicolumn{1}{|c|}{ Objetivo } & \multicolumn{1}{c|}{ Teste } & \multicolumn{1}{c|}{ Hipótese Nula $\left(\mathbf{H}_{\mathbf{0}}\right)$} \\
\hline Efeitos fixos ou Efeitos aleatórios & Hausman & Efeitos aleatórios \\
\hline Correlação dos resíduos & Breusch-Godfrey/Wooldridge & Não há correlação \\
\hline Normalidades dos resíduos & Shapiro- Wilk & Dados normais \\
\hline Homoscedasticidade dos resíduos & Breusch-Pagan & Dados homoscedásticos \\
\hline
\end{tabular}

Quadro 4: Testes empregados para análise dos modelos.

Fonte: Elaborado dos autores.

Por fim, ressalta-se que para a operacionalização da análise de regressão com dados em painel empregou-se o software $R$, versão 3.4.2. Em específico, usou-se o pacote plm. Croissant e Millo (2008) destacam que se trata de um pacote do software R que visa tornar a estimação de modelos desse tipo mais diretas. $\mathrm{O}$ pacote $\mathrm{plm}$ fornece funções para estimar uma ampla variedade de modelos e realizar inferências robustas (Croissant \& Millo, 2008).

\section{APRESENTAÇÃO E ANÁLISE DOS RESULTADOS}

Nesta seção são apresentados e discutidos os resultados obtidos a partir da pesquisa empírica. Na Tabela 2 são apresentadas as estatísticas descritivas das variáveis métricas analisadas, se-

\begin{tabular}{|c|c|c|c|c|c|c|c|c|c|c|}
\hline Estatísticas & DR & COL & ANT & DEP & ROA & TAM & NCG & INVPER & MAF & CFIN \\
\hline Modalidade & \multicolumn{10}{|c|}{ COM } \\
\hline Mínimo & 0,00 & 0,00 & 0,00 & 0,00 & $-0,39$ & 12,47 & $-0,30$ & 10,09 & 0,10 & $-0,19$ \\
\hline $1^{\mathrm{o}}$ quartil & 0,02 & 0,57 & 0,02 & 0,30 & 0,05 & 16,41 & 0,00 & 14,54 & 0,92 & 0,02 \\
\hline Mediana & 0,04 & 0,72 & 0,06 & 0,34 & 0,09 & 17,07 & 0,05 & 15,52 & 1,42 & 0,04 \\
\hline Média & 0,18 & 0,69 & 0,11 & 0,35 & 0,22 & 17,22 & 0,06 & 15,60 & 3,36 & 0,06 \\
\hline $3^{\circ}$ quartil & 0,08 & 0,84 & 0,15 & 0,38 & 0,15 & 17,97 & 0,11 & 16,72 & 2,32 & 0,08 \\
\hline Máximo & 3,74 & 1,00 & 1,00 & 1,62 & 3,74 & 21,53 & 0,51 & 20,79 & 813,37 & 0,50 \\
\hline DP & 0,49 & 0,21 & 0,14 & 0,09 & 0,49 & 1,29 & 0,10 & 1,56 & 26,92 & 0,05 \\
\hline Modalidade & \multicolumn{10}{|c|}{ MDG } \\
\hline Mínimo & 0,00 & 0,00 & 0,00 & 0,02 & $-0,50$ & 11,48 & $-0,47$ & 7,32 & 0,00 & 0,00 \\
\hline $1^{o}$ quartil & 0,03 & 0,38 & 0,00 & 0,27 & 0,06 & 15,17 & $-0,02$ & 13,05 & 0,72 & 0,02 \\
\hline Mediana & 0,08 & 0,72 & 0,02 & 0,33 & 0,13 & 16,40 & 0,07 & 14,62 & 1,42 & 0,04 \\
\hline Média & 0,32 & 0,61 & 0,11 & 0,36 & 0,34 & 16,37 & 0,10 & 14,47 & 3,15 & 0,07 \\
\hline $3^{-}$quartil & 0,17 & 0,90 & 0,10 & 0,41 & 0,25 & 17,59 & 0,19 & 15,94 & 2,70 & 0,08 \\
\hline Máximo & 5,77 & 1,00 & 1,00 & 1,31 & 5,74 & 22,11 & 0,78 & 21,64 & 243,95 & 1,02 \\
\hline DP & 0,70 & 0,34 & 0,21 & 0,17 & 0,70 & 1,76 & 0,18 & 2,26 & 11,05 & 0,09 \\
\hline
\end{tabular}
paradas por modalidade.

Tabela 2: Estatísticas descritivas das variáveis métricas analisadas.

Fonte: Elaborado pelos autores.

Verifica-se que, em média, as OPS classificadas como MDG distribuíram uma porção maior de seus resultados em relação àquelas classificadas como COM. Nesse caso, é importante ressaltar 
que os cooperados recebem outros benefícios da cooperativa, além da distribuição das sobras, o que poderia explicar essa menor distribuição média de resultados. Salienta-se ainda que, na média, àquelas operadoras apresentaram um maior retorno em relação às cooperativas, contudo, o risco financeiro médio das operadoras de ambas as modalidades parece bem semelhantes. Ademais, destaca-se que a variável dependente e as de regulação apresentaram um menor nível de volatilidade, mensurada pelo desvio-padrão (DP), em relação às variáveis de controle nas duas modalidades estudadas.

Por sua vez, na Tabela 3, são apresentados os resultados dos modelos estimados para cada uma das modalidades de OPS estudadas. Em ambos os casos procedeu-se ao Teste de Hausman para escolha do modelo de efeitos fixos ou efeitos aleatórios, sendo que este foi preferido no caso das operadoras classificadas como MDG, e àquele no caso das COM. Após estimação dos modelos, para sua validação, procedeu-se com a análise da normalidade dos resíduos, heteroscedasticidade e correlação serial.

O teste de Shapiro-Wilk apontou para a não rejeição da hipótese nula, indicando que os resíduos seguem uma distribuição normal no caso do modelo estimado para as operadoras da modalidade COM. Já no caso do teste de Breusch-Pagan, os p-valores obtidos indicaram que a variância dos erros em ambos os modelos era homoscedástica no que se refere ao modelo da modalidade supracitada.

Por fim, o teste de autocorreção dos resíduos de Breusch Godfrey foi elaborado sob a hipótese que os termos de erro não apresentam autocorreção de primeira ordem, e verificou-se a ausência de autocorrelação em ambos os modelos estimados. Para correção dos problemas relacionados à normalidade e a homoscedasticidade do modelo estimado para as operadoras da modalidade MDG, empregou-se o modelo de Arellano (1993) como citado em Arellano (2003), para corrigir tais disfunções.

Tabela 3: Resultados dos modelos estimados

\begin{tabular}{|c|c|c|c|c|}
\hline \multirow{3}{*}{$\begin{array}{c}\text { Modalidade } \\
\text { Modelo } \\
\text { Variável } \\
\end{array}$} & \multicolumn{2}{|c|}{$\mathrm{COM}$} & \multicolumn{2}{|c|}{ MDG } \\
\hline & \multicolumn{2}{|c|}{ Modelo de efeitos fixos } & \multicolumn{2}{|c|}{ Modelo de efeitos aleatórios } \\
\hline & Coeficientes & P-valor & Coeficientes & P-valor \\
\hline Intercepto & & & $0,16^{* *}$ & 0,04 \\
\hline RANS & & & $-0,03$ & 0,12 \\
\hline CDR1 & & & 0,04 & 0,38 \\
\hline CDR2 & & & 0,05 & 0,36 \\
\hline CDR3 & $-0,13^{* *}$ & 0,01 & 0,02 & 0,50 \\
\hline CDR4 & 0,00 & 0,99 & 0,01 & 0,53 \\
\hline CDR5 & $-0,01$ & 0,55 & $-0,04^{* *}$ & 0,02 \\
\hline COL & $-0,01$ & 0,71 & 0,02 & 0,48 \\
\hline ANT & $-0,09^{* *}$ & 0,01 & $-0,04$ & 0,23 \\
\hline DEP & 0,02 & 0,72 & $-0,01$ & 0,75 \\
\hline ROA & $0,99 *$ & 0,00 & $0,97^{*}$ & 0,00 \\
\hline TAM & $-0,07^{*}$ & 0,00 & $-0,01^{* *}$ & 0,01 \\
\hline NCG & $0,13 *$ & 0,00 & $-0,01$ & 0,83 \\
\hline INVPER & $0,02 *$ & 0,01 & $0,01^{* * *}$ & 0,10 \\
\hline MAF & $0,00 *$ & 0,00 & $0,00^{*}$ & 0,00 \\
\hline CFIN & $-0,06$ & 0,36 & $-0,01$ & 0,93 \\
\hline Hausman & $32,40^{*}$ & 0,00 & 3,49 & 0,63 \\
\hline Breusch-Godfrey/Wooldridge & 0,00 & 0,97 & $14,99^{* * *}$ & 0,08 \\
\hline Shapiro- Wilk & $0,75^{* * *}$ & 0,05 & $8,64^{* *}$ & 0,02 \\
\hline Breusch-Pagan & 28,30 & 0,23 & $29,67^{* *}$ & 0,01 \\
\hline $\mathrm{R}^{2}$ & $98,15 \%$ & & $96,21 \%$ & \\
\hline
\end{tabular}

Nota: Nível de significância: $1 \%\left({ }^{*}\right), 5 \%\left(^{* *}\right)$ e $10 \%\left(^{* * *}\right)$.

Fonte: Elaborado pelos autores. 
Primeiramente verifica-se que ambos os modelos estimados apresentaram um alto poder explicativo sobre o fenômeno de distribuição de resultados (vide valores do $\mathrm{R}^{2}$ ), em ambas as modalidades de OPS. Dessa forma, pode-se verificar que as variáveis selecionadas para compor os modelos são adequadas para a explicação do fenômeno nessas organizações. Ademais, constata-se que diversas variáveis de controle foram consideradas significantes, tanto no que se refere às operadoras classificadas como MDG quanto àquelas classificadas como COM. Dessa forma, apesar das naturezas jurídicas distintas dessas organizações, o comportamento das variáveis é semelhante ao das empresas nas quais tais variáveis foram amplamente testadas.

No que tange à variável ROA, observou-se uma relação positiva e significante com a distribuição de resultados em ambas as modalidades de operadoras. Tal resultado vai ao encontro do esperado com base na literatura, conforme autores como French e Fama (2001) e Forti et al. (2015). Assim, operadoras mais rentáveis tenderam a distribuir um maior volume de resultados. Por outro lado, observou-se uma relação negativa e significante entre a variável TAM e a DR. Tal resultado contraria o esperado com base na literatura, de acordo com autores como French e Fama (2001), Ferreira et al. (2010) e Vancin e Procianoy (2016). Nesse caso, quanto maior o porte da OPS (de ambas as modalidades), menor tendeu a ser o nível de distribuição de resultados.

Por sua vez, apenas no que se refere às cooperativas, observaram-se relações positivas e significantes (a 5,0\%) no que tange às variáveis NCG e INVPER. Tal resultado, a priori, contraria o exposto na literatura, com base em autores como Woorldrige e Gosh (1985) e Januzzi et al. (2015). Uma explicação possível para o coeficiente observado em relação à variável NCG se relaciona com o fato de que recursos em demasia podem ter sido distribuídos pelas organizações e pressionando aquela necessidade, gerando uma relação positiva entre as duas variáveis. Já no caso da variável INVPER, as organizações que teriam mais condições de distribuir maiores resultados seriam provavelmente as mesmas que teriam mais condições de investimento em ativos de longo prazo de maturação.

Enquanto isso, a variável MAF apresentou um coeficiente positivo e significante com a distribuição dos resultados de ambas as modalidades de OPS (COM e MDG). Segundo a literatura, esperar-se-ia uma relação negativa (Ferreira et al., 2010). Contudo, empresas mais alavancadas poderiam ter um maior nível de desempenho, gerando um maior volume de recursos a distribuir.

Já no que se relaciona exclusivamente às variáveis ligadas à regulação, observa-se que apenas algumas foram significantes nos modelos estimados. No que tange às OPS classificadas como COM, verificou-se uma relação negativa e significante entre as variáveis CDR3 (atuação na Região 3) e a distribuição de resultados. Nesse caso, trata-se de OPS que atuam em apenas um Estado da federação (com exceção de São Paulo), o que reduziria o custo de capital dessas organizações, e, consequentemente, um menor volume de recursos para distribuir.

Ademais, verificou-se uma relação negativa e significante entre as variáveis ANT e DR, no que se refere às operadoras da modalidade supracitada. Tal constatação vai contra a base na hipótese desenvolvida, já que se esperaria uma maior capacidade das OPS em lidar com uma distribuição de resultados mais favorável, devido à flexibilidade dada pelos contratos firmados antes da criação da ANS.

Por fim, no que tange às OPS classificadas como MDG, verificou-se uma relação negativa e estatisticamente significante entre a atuação das operadoras na Região 5 e seu nível de distribuição de resultados. Tratam-se, assim, de operadoras que atuaram em grupo de municípios com exceção daqueles listados na Região 4 (São Paulo, Rio de Janeiro, Belo Horizonte, Porto Alegre, Curitiba ou Brasília), ou seja, os grupos com maiores níveis de renda do país. Dessa forma, assim como no caso da atuação das operadoras cooperativas na Região 3, o menor custo de oportunidade do capital de atuação na Região 5 por parte daquelas classificadas como MDG explicaria um menor nível de distribuição de resultados. 
O Quadro 5 destaca as conclusões sobre cada uma das hipóteses desenvolvidas na seção 2.3. Observa-se que foi confirmada apenas a Hipótese 3. Apesar da variável ANT ter sido considerada significante no caso das operadoras classificadas como COM, o coeficiente estimado teve sinal distinto do esperado com base na hipótese formulada.

\begin{tabular}{|c|l|}
\hline Hipótese & \multicolumn{1}{c|}{ Conclusão } \\
\hline H1 & $\begin{array}{l}\text { Não se pode afirmar que a proporção de contratos antigos em suas carteiras tem relação } \\
\text { positiva e significante com a distribuição de resultados das OPS estudadas. }\end{array}$ \\
\hline H2 & $\begin{array}{l}\text { Não se pode afirmar que a proporção de beneficiários de planos coletivos em suas carteiras } \\
\text { tem relação positiva e significante com a distribuição de resultados das OPS estudadas. }\end{array}$ \\
\hline H3 & $\begin{array}{l}\text { A região de atuação da OPS tem relação significante com a distribuição de resultados das } \\
\text { OPS estudadas. }\end{array}$ \\
\hline H4 & $\begin{array}{l}\text { Não se pode afirmar que o fato de a OPS ter sido registrada após a criação da ANS tem rela- } \\
\text { ção negativa e significante com a distribuição de resultados das OPS estudadas. }\end{array}$ \\
\hline H5 & $\begin{array}{l}\text { Não se pode afirmar que a razão de dependência das OPS tem relação negativa e significante } \\
\text { com a distribuição de resultados das OPS estudadas. }\end{array}$ \\
\hline
\end{tabular}

Quadro 5: Resumo das conclusões referentes às hipóteses desenvolvidas sobre os efeitos da regulação sobre a distribuição de resultados de diferentes modalidades de OPS.

Fonte: elaborado pelos autores.

\section{CONSIDERAÇÕES FINAIS}

Este artigo apresentou os resultados de uma pesquisa que visou analisar os efeitos da regulação da ANS sobre a distribuição de resultados em OPS das modalidades COM e MDG entre os anos de 2010 e 2016. A pesquisa, que é classificada essencialmente como descritiva, quantitativa e causal, foi desenvolvida empregando dados secundários (financeiros e operacionais), coletados junto à ANS, das operadoras das referidas modalidades.

Constatou-se que, em média, as OPS classificadas como MDG distribuíram uma porção maior de seus resultados em relação àquelas classificadas como COM. Ressalta-se ainda que, na média, àquelas operadoras apresentaram um maior retorno em relação às cooperativas, contudo, o risco financeiro médio das operadoras de ambas as modalidades foi semelhante. Verificou-se que ambos os modelos estimados apresentaram um alto poder explicativo sobre o fenômeno de distribuição de resultados em ambas as modalidades de OPS. Dessa forma, pode-se verificar que as variáveis selecionadas para compor os modelos foram adequadas para a explicação do fenômeno nessas organizações.

Ademais, observou-se que diversas variáveis de controle foram consideradas significantes, tanto no que se refere às operadoras classificadas como MDG, quanto àquelas classificadas como COM. Assim, apesar das naturezas jurídicas distintas dessas organizações, o comportamento das variáveis é semelhante ao das empresas nas quais tais métricas foram amplamente testadas, conforme a literatura nacional e internacional. Verificou-se que a lucratividade foi positiva e significativamente relacionada à distribuição de resultado em ambas as modalidades de OPS estudadas, indo ao encontro do esperado com base na literatura. Contudo, algumas outras variáveis de controle apresentaram sinais diversos do esperado com base no mainstream acadêmico, sendo que tais divergências podem estar relacionadas às peculiaridades da atuação das OPS analisadas.

No que se refere às variáveis relacionadas à regulação, observou-se que a região de atuação das mesmas, conforme normatizado pela RN №. 209 (2009), foi a principal variável determinante na distribuição de resultados. Neste caso, observou-se que as operadoras classificadas como MDG que atuavam na Região 5 e as cooperativas médicas que atuavam na Região 3 tenderam a distribuir um menor volume de resultados em relação às demais. Tais regiões excluem centros com maior número de beneficiários e com maior poder aquisitivo como o Estado de São Paulo (Região 2) e as cidades de São Paulo, Rio de Janeiro, Belo Horizonte, Porto Alegre, Curitiba ou Brasília (Região 4). 
Por outro lado, observou-se uma menor distribuição de resultados por parte das operadoras da modalidade COM que possuíam uma maior proporção de planos antigos (variável ANT) em suas carteiras, o que não era esperado conforme a literatura sobre o tema.

Podem ser citadas diversas contribuições da pesquisa para o conhecimento na área estudada. Primeiramente, auxilia a suprir uma lacuna teórica na literatura brasileira sobre a distribuição de resultados em organizações com capital essencialmente fechado, assim como a falta de estudos visando relacionar a regulação como variável determinante nesse fenômeno. Ademais, o estudo evidenciou a relação entre algumas normas regulatórias e a distribuição de resultados em OPS. A pesquisa desenvolvida também demonstrou a validade de variáveis tradicionais em modelos desenvolvidos no ambiente corporativo para explicar o fenômeno de distribuição de resultados nessas organizações. Outra contribuição da pesquisa foi a proposição de variáveis regulatórias para auxiliar na explicação desse fenômeno em organizações do setor de saúde suplementar.

Entretanto, apesar das contribuições supracitadas, é relevante destacar as limitações do estudo desenvolvido. Primeiramente, as variáveis utilizadas limitam o presente estudo, por se tratarem de empresas de capital aberto, no entanto, é preciso ressaltar que, por não possuir variáveis alternativas que pudessem ser utilizadas comparativamente, estas se fizeram necessárias. Ressaltase, ainda, que a amostra é limitada aos dados disponibilizados por parte da ANS. Ademais, apesar dos esforços no desenvolvimento das variáveis de regulação, as mesmas são limitadas diante dos dados disponíveis para o seu cálculo. Nesse caso, é importante salientar que se trata de uma limitação inerente a estudos como este (French \& Fama, 2002).

Diante das contribuições e das limitações citadas, pesquisas futuras poderiam testar as variáveis de regulação propostas no estudo ora apresentado em outros contextos (novas amostras e/ou diferentes horizontes temporais). Além disso, tais estudos poderiam propor novas variáveis a serem exploradas no que tange à regulação das organizações estudadas. Por fim, estudos sobre as modalidades de OPS exclusivamente odontológicas poderiam ser abordadas em suas especificidades, no intuito de observar as diferenças dos efeitos da regulação da ANS sobre essas organizações.

\section{REFERÊNCIAS}

Ang, J. S., Fatemi, A., \& Tourani-Rad, A. (1997). Capital structure and dividend policies of Indonesian firms. Pacific-Basin Finance Journal, 5(1), 87-103.

Agência Nacional de Saúde Suplementar - ANS. (2019). Sala de situação. Recuperado em 20 de fevereiro, 2019, de http://www.ans.gov.br/perfil-do-setor/dados-e-indicadores-do-setor/salade-situacao.

Agência Nacional de Saúde Suplementar - ANS. (2018) Registro de operadora. Recuperado em 16 de janeiro, 2018, de http://www.ans.gov.br/planosde-saude-e-operadoras/espaco-daoperadora/registro-e-manutencao-de-operadoras-eprodutos/registro-de-operadora.

Agência Nacional de Saúde Suplementar - ANS (2016). Manual da Sala de Situação da ANS: Conceitos e Fontes de Dados - Maio 2016. Recuperado em 11 de setembro de 2019, de http://www.ans.gov.br/images/stories/Materiais_para_pesquisa/Perfil_setor/Dados_e_indicador es_do_setor/Manual-Sala-de-Situacao.pdf.

Arellano, M. (2003). Panel Data Econometrics: Advanced Texts in Econometrics. Oxford: Oxford University Press.

Associação Brasileira de Planos de Saúde - ABRAMGE. (2015). Custo cresce mais que receita, dizem planos. Recuperado em 11 de janeiro, 2018, de http://blog.abramge.com.br/mundocorporativo/economia-mercado/custo-cresce-mais-que-receita-dizem-planos/.

Barroso, M. F. G., \& Bialoskorski Neto, S. (2010). Distribuição de resultados em cooperativas de crédito rural no Estado de São Paulo. Organizações Rurais \& Agroindustriais, 12(2), 290-307. 
Chiarello, T. C., Silva, T. P., \& Nakamura, W. T. (2014). Efeito das estratégias financeiras alinhado à política de dividendos das empresas de propriedade familiar e não familiar brasileiras. Advances in Scientific and Applied Accounting, 7(3), 432-452.

Cornett, M. M., Fayman, A., Marcus, A. J., \& Tehranian, H. (2011). Dividends, maturity, and acquisitions: Evidence from a sample of bank IPOs. Review of Financial Economics, 20(1), 11-21.

Croissant, Y., \& Millo, G. (2008). Panel data econometrics in R: The plm package. Journal of statistical software, 27(2), 1-43.

Damodaran, A. (2004). Finanças corporativas: Teoria e Prática (2a ed.). Porto Alegre: Bookman.

Fama, E. F., \& French, K. R. (2001). Disappearing dividends: changing firm characteristics or lower propensity to pay?. Journal of Financial Economics, 60(1), 3-43.

Fama, E. F., \& French, K. R. (2002). Testing trade-off and pecking order predictions about dividends and debt. The Review of Financial Studies, 15(1), 1-33.

Fávero, L. P. (2015). Análise de Dados: Modelos de Regressão com Excel®, Stata® e SPSS®. Rio de Janeiro: Elsevier.

Ferreira, W. O., Jr., Nakamura, W.T., Martin, D.M.L., \& Bastos, D. D. (2010). Evidências empíricas dos fatores determinantes das políticas de dividendos das firmas listadas na Bovespa. FACEF Pesquisa-Desenvolvimento e Gestão, 13(2), 190-203.

Fiorati, A. R. S., Garcia, F. G., \& Tambosi, E., Filho. (2007, setembro). Dividendos e juros sobre capital próprio: sinalização de lucratividade futura? Um estudo no mercado brasileiro 1999-2004. Anais do Encontro Nacional da Associação Nacional dos Programas de Pós-Graduação em Administração, Rio de Janeiro, RJ, Brasil, 31.

Fonteles, I. V., Peixoto, C. A., Jr., Vasconcelos, A. C., \& De Luca, M. M. M. (2012). Política de dividendos das empresas participantes do Índice Dividendos da BM\&FBovespa. Contabilidade Vista $\mathcal{E}$ Revista, 23(3), 173-204.

Forti, C. A. B., Peixoto, F. M., \& Lima e Alves, D. (2015). Fatores determinantes do pagamento de dividendos no Brasil. Revista de Contabilidade e Finanças - USP, 26(68), 167-180.

Gelbcke, E. R., Santos, A., Iudícibus, S., \& Martins, E. (2018). Manual de contabilidade societária: aplicável a todas as sociedades: de acordo com as normas internacionais e do CPC. (3a ed.). São Paulo: Atlas.

Gujarati, D. N., \& Porter, D. C. (2011). Econometria básica. (5a ed.). Porto Alegre: AMGH.

Holanda, A. P., \& Coelho, A. C. D. (2012). Dividendos e efeito clientela: evidências no mercado brasileiro. RAE-Revista de Administração de Empresas, 52(4), 448-463.

Januzzi, F.V., Avelar, E. A., \& Amaral, H. F. (2015). Análise da influência de variáveis contábeis e de mercado sobre dividendos pagos. Revista FSA, 12(5), 26-48.

Leal, R. M. (2014). O mercado de saúde suplementar no Brasil: regulação e resultados econômicos dos planos privados de saúde. Anais da Jornada de Estudos de Regulação, Rio de Janeiro, RJ, Brasil, 8.

Lei n. 5.764, de 16 de dezembro de 1971 (1971). Define a Política Nacional de Cooperativismo, institui o regime jurídico das sociedades cooperativas, e dá outras providências. Brasília. DF. Recuperado em 18 janeiro, 2019, de http://www.planalto.gov.br/ccivil_03/LEIS/L5764.htm.

Lei n. 9.249, de 26 de dezembro de 1995 (1995). Altera a legislação do imposto de renda das pessoas jurídicas, bem como da contribuição social sobre o lucro líquido, e dá outras providências. Brasília. DF. Recuperado em 18 janeiro, 2019, de http://www.planalto.gov.br/ccivil_03/LEIS/L9249.htm.

Lei n. 9.956, de 03 de junho de 1998 (1998). Dispõe sobre os planos e seguros privados de assistência à saúde. Brasília, 1998. Recuperado em 18 janeiro, 2019, de http://www.planalto.gov.br/ccivil_03/leis/L9656compilado.htm 
Lei n. 9.961, de 28 de janeiro de 2000 (2000). Cria a Agência Nacional de Saúde Suplementar - ANS e dá outras providências. Brasília, DF. Recuperado em 10 outubro, 2018, de http://www.planalto.gov.br/ccivil_03/leis/L9961.htm.

Lei n. 12.527, de 18 de novembro de 2011 (2011). Regula o acesso a informações previsto no inciso XXXIII do art. 5o, no inciso II do $\S 3^{\circ}$ do art. 37 e no $\S 2^{\circ}$ do art. 216 da Constituição Federal; altera a Lei $\mathrm{n}^{\mathrm{o}}$ 8.112, de 11 de dezembro de 1990; revoga a Lei $\mathrm{n}^{\mathrm{o}}$ 11.111, de 5 de maio de 2005, e dispositivos da Lei no 8.159, de 8 de janeiro de 1991; e dá outras providências. Brasília, DF. Recuperado em 18 janeiro, 2019, de http://www.planalto.gov.br/ccivil_03/_ato20112014/2011/lei/112527.htm

Leite, M., Bambino, A. C., \& Hein, N. (2017). Relação entre Política de Dividendos e Desempenho econômico financeiro em empresas brasileiras e chilenas. Revista de Gestão, Finanças e Contabilidade, 7(1), 205-221.

Machado (2009). Cooperativas médicas. Brasília. 2009. Recuperado em 18 janeiro, 2019, de http://www2.camara.leg.br/atividade-legislativa/estudos-e-notas-tecnicas/publicacoes-daconsultoria-legislativa/areas-da-conle/tema19/H-Coord_Legislativa-Setex-Internet2009 1031.pdf

Malhotra, N. K., \& Birks, D. F. (2007) Marketing Research: An Applied Approach (3a ed.). Harlow: Prentice Hall.

Mann, P. S. (2006). Introdução à estatística. (3a ed.). Rio de Janeiro: LTC.

Monteiro, A. A. S. (2003). Fluxos de caixa e capital de giro: uma adaptação do modelo de Fleuriet. Pensar Contábil, 6 (20), 27-33.

Pinheiro, I. C. B., Peleias, I. R., Silva, A. F., \& Martins, E. (2015). Efeitos da regulação econômicofinanceira nas estratégias de financiamento das operadoras de planos de saúde. Revista Universo Contábil, 11(2), 108-127.

Resolução de Diretoria Colegiada (RDC) n. 39, de 27 de outubro de 2000 (2000). Dispõe sobre a definição, a segmentação e a classificação das Operadoras de Planos de Assistência à Saúde. Agência Nacional de Saúde Suplementar. Recuperado em 20 de fevereiro, 2019, de http://www.ans.gov.br/component/legislacao/?view=legislacao\&task=TextoLei\&format=raw \&id=Mzgw

Resolução Normativa (RN) n. 209, de 22 de dezembro de 2009 (2009). Dispõe sobre os critérios de manutenção de Recursos Próprios Mínimos e constituição de Provisões Técnicas a serem observados pelas operadoras de planos privados de assistência à saúde. 2009. Recuperado em 16 de fevereiro, 2018,

de http://www.ans.gov.br/component/legislacao/?view=legislacao\&task=TextoLei\&format=raw\&i $\mathrm{d}=\mathrm{MTU} 3 \mathrm{MQ}=$

Ross, S. A., Westerfield, R. W., Jaffe, J., \& Lamb, R. (2015). Administração financeira. AMGH Editora.

Sampieri, R. H., Collado, C. F., \& Lucio, P. B. (2006). Metodologia de pesquisa. (3a ed.) São Paulo: McGraw-Hill.

Santos, J. F., \& Galvão, K. S. (2015). Política de dividendos e seus fatores determinantes: evidenciando a ausência de consenso teórico-empírico. Revista FAE, 18(1), 52-69.

Seidel, A., \& Kume, R. (2003). Contabilização das variações da necessidade de capital de giro. Revista Contabilidade E Finanças, 14(31), 66-77.

Silva, C. P., Jr., \& Machado, M. A. (2015). A influência da política de dividendos sobre a volatilidade das ações. Revista de Contabilidade E Controladoria, 7(3), 8-20.

Silva, V. V., Lobel, E. (2016). Análise do desempenho econômico-financeiro de operadoras de planos privados de saúde do setor brasileiro de saúde. Revista de Administração Hospitalar e Inovação em Saúde,13(3), 1-21. 
Supremo Tribunal Federal. (2003) Ação direta de inconstitucionalidade (ADI) - 1931. Recuperado em 10 de fevereiro, 2017, em: http://www.stf.jus.br/portal/peticaoInicial/ verPeticaoInicial.asp?base=ADIN\&s1=1931\&processo $=1931$.

Ugá, M. A. D., Lima, S. L. M., Portela, M. C., Vasconcellos, M. M., Barbosa, P. R., \& Gerschman, S. (2008). Uma análise das operadoras de planos próprios de saúde dos hospitais filantrópicos no Brasil. Cadernos de Saúde Pública, 24(1), 157-168.

Vancin, D. F., \& Procianoy, J. L. (2016). Os fatores determinantes do pagamento de dividendos: o efeito do obrigatório mínimo legal e contratual nas empresas brasileiras. Revista Brasileira de Finanças, 14(1), 89-123.

Varella, D., \& Ceschin, M. (2014). A saúde dos planos de saúde: os desafios da assistência privada no Brasil. São Paulo: Paralela.

Veloso, G. G., \& Malik, A. M. (2010). Análise do desempenho econômico-financeiro de empresas de saúde. RAE-eletrônica, 9(1), 1-22.

Viana, D. B. C., Jr., \& Ponte, V. M. R. (2016). Políticas de dividendos: um estudo comparativo entre empresas brasileiras e norte-americanas. Revista Universo Contábil, 12(1), 25-44.

Woolridge, J. R., \& Ghosh, C. (1985). Dividend cuts: do they always signal bad news?. Midland Corporate Finance Journal, 3(2), 20-32.

Xavier, D. O. (2017). Variáveis determinantes do desempenho econômico-financeiro de operadoras de planos de saúde. Dissertação de Mestrado em Administração, Universidade Federal de Minas Gerais, Belo Horizonte, MG, Brasil. Disponível: http://www.bibliotecadigital.ufmg.br/dspace/handle/1843/BUBD-ANYP9C. 